\title{
Management of Autosomal Dominant Polycystic Kidney Disease (ADPKD) During Pregnancy: Risks and Challenges
}

This article was published in the following Dove Press journal: International Journal of Women's Health

\author{
Lucy McBride (D) \\ Catherine Wilkinson ${ }^{2}$ \\ Shilpanjali Jesudason ${ }^{2,3}$ \\ 'Women's and Babies' Division, Women's \\ and Children's Hospital, Adelaide, SA, \\ Australia; ${ }^{2}$ Central and Northern \\ Adelaide Renal and Transplantation \\ Services (CNARTS), Royal Adelaide \\ Hospital, Adelaide, SA, Australia; ${ }^{3}$ Faculty \\ of Health and Medical Sciences, \\ University of Adelaide, Adelaide, SA, \\ Australia
}

\begin{abstract}
Autosomal dominant polycystic kidney disease (ADPKD) affects up to 1 in 1000 people. The disease is characterized by the progressive development of cysts throughout the renal parenchyma due to inherited pathogenic variants in genes including PKD1 or PKD2 and eventually leads to gradual loss of renal function, along with manifestations in other organ systems such as hepatic cysts and intracranial aneurysms. ADPKD management has advanced considerably in recent years due to genetic testing availability, pre-implantation genetic diagnosis technology and new therapeutic agents. Renal disease in pregnancy is recognised as an important risk factor for adverse maternal and fetal outcome. Women with ADPKD and health professionals face multiple challenges in optimising outcomes during the pre-pregnancy, pregnancy and post-partum periods.
\end{abstract}

Keywords: autosomal dominant polycystic kidney disease, chronic kidney disease, cystic kidney disease, pregnancy

\section{Autosomal Dominant Polycystic Kidney Disease}

Autosomal dominant polycystic kidney disease (ADPKD) is the most common form of monogenic kidney disease and cystic kidney disease, affecting around one in 1000 to one in 2500 individuals. ${ }^{1,2}$ Males and females are equally affected. The disease is characterised by the development of cysts throughout the renal parenchyma from early in life leading to progressive loss of renal function in many patients. ADPKD accounts for $5-10 \%$ of the patients with end-stage kidney disease (ESKD), ${ }^{3,4}$ usually occurring around the sixth decade. Hypertension is common, affecting most people with enlarged kidneys or biomedical features of chronic kidney disease (CKD). Complications as a result of cystic formation and growth include pain, cyst hemorrhage and hematuria, urinary tract infection (UTI), cyst infection, and nephrolithiasis. Although renal consequences predominate, extra-renal disease occurs, including polycystic liver disease, intracranial aneurysm and cardiac disease.

ADPKD is caused by pathologic variants in PKD1 and PKD2 genes. PKD1, located on chromosome 16, encodes Polycystin-1 (PC1) and PKD2, located on chromosome 4, encodes polycystin-2 (PC2). The polycystins are a subfamily of protein channels that regulate intracellular calcium signalling. Polycystins are expressed in multiple tissues, including renal tubular epithelium, hepatic bile ducts and pancreatic ducts. Both PC1 and PC2 are found on the primary cilia.
Correspondence: Lucy McBride Email Lucy.McBride2@nh.org.au 
More than 1500 different pathogenic variants of $P K D 1$ and $P K D 2$ have been identified and indexed on the ADPKD mutation database. ${ }^{5}$ Mutations in $P K D 1$ versus PKD2 generally lead to more severe disease, with an earlier average age of ESKD. ${ }^{6}$ A proportion of people with ADPKD will not have a family history of the disease due to de novo mutations (5-10\%), mosaicism, or undiagnosed milder disease from certain mutations in family members.

ADPKD has high phenotypic variability. All affected people develop cysts but with variable occurrence and progression of renal insufficiency. In addition to the affected locus, other genetic factors impact phenotype, and affected families may have significantly discordant disease severity, suggesting a role for environmental factors. ${ }^{6,7}$ Clinical factors have been associated with disease severity and outcomes, such as total kidney volume (TKV), blood pressure, renal function and intracranial aneurysm/haemorrhage.

\section{Chronic Kidney Disease}

$\mathrm{CKD}$ is an abnormality in kidney structure or function, present for greater than 3 months. CKD is classified into stages from 1 to 5, which indicate likelihood to develop complications related to $\mathrm{CKD}$ including progression to ESKD, anemia, adverse reactions to renally excreted drugs, cardiovascular events and all-cause death. Classification (illustrated in Figure 1) takes into account glomerular filtration rate and degree of albuminuria. ${ }^{8,9}$

By definition, all patients with ADPKD have at least CKD stage 1 given the abnormality in kidney structure.

In Australia, an estimation of glomerular filtration rate (eGFR) is calculated by using the CKD-EPI equation. ${ }^{10}$ This formula uses variables of patient age, gender and creatinine; is easily calculated; and is now mandatory to report with biochemistry. The eGFR is only valid for people over 18 years of age and is not validated for use in pregnancy.

\section{ADPKD and Women of Child-Bearing Age}

As most ( $>80 \%)$ ADPKD patients are commenced on dialysis over the age of 45 years, ${ }^{4}$ ADPKD is uncommonly seen in Australian women who receive dialysis or have a kidney transplant in pregnancy. ${ }^{11,12}$ However, women with ADPKD may have earlier-stage CKD during pregnancy with hypertension, proteinuria, and mild renal impairment.

Prognosis of CKD by GFR and Albuminuria Categories: KDIGO 2012

\begin{tabular}{|c|c|c|c|c|c|c|}
\hline & \multirow{2}{*}{$\begin{array}{l}<30 \mathrm{mg} / \mathrm{g} \\
<3 \mathrm{mg} / \mathrm{mmol}\end{array}$} & \multirow{2}{*}{$\begin{array}{c}30-300 \mathrm{mg} / \mathrm{g} \\
3-30 \mathrm{mg} / \mathrm{mmol}\end{array}$} & \multirow{2}{*}{$\begin{array}{c}>300 \mathrm{mg} / \mathrm{g} \\
>30 \mathrm{mg} / \mathrm{mmol}\end{array}$} \\
\hline & & & & & & \\
\hline \multirow{6}{*}{ 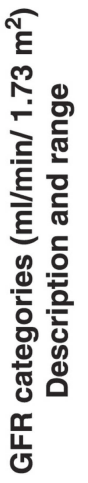 } & G1 & Normal or high & $\geq 90$ & & & \\
\hline & G2 & Mildly decreased & $60-89$ & & & \\
\hline & G3a & $\begin{array}{l}\text { Mildly to moderately } \\
\text { decreased }\end{array}$ & $45-59$ & & & \\
\hline & G3b & $\begin{array}{l}\text { Moderately to } \\
\text { severely decreased }\end{array}$ & $30-44$ & & & \\
\hline & G4 & Severely decreased & $15-29$ & & & \\
\hline & G5 & Kidney failure & $<15$ & & & \\
\hline
\end{tabular}

Figure I Prognosis of CKD by GFR and Albuminuria Categories.

Notes: Green indicates low risk, yellow indicates moderate risk, orange indicates high risk, red indicates very high risk. Image reproduced with permission from NKF KDOGI Guidelines 2012. Available from https://kdigo.org/guidelines/ckd-evaluation-and-management/ ${ }^{8}$

Abbreviations: CKD, chronic kidney disease; GFR, glomerular filtration rate; KDIGO, Kidney Disease: Improving Global Outcomes. 
Discussions regarding pregnancy should be a routine part of clinical care for all women with CKD of child-bearing age. ${ }^{13}$ All chronic kidney diseases, including ADPKD, are known to be associated with higher risk pregnancies, particularly preeclampsia and prematurity. Assessment of renal function, proteinuria, and blood pressure is essential in individualising risk assessment. Consider renal ultrasound if not done within 1 year to assess cyst's size and to use as a baseline scan for comparison in pregnancy. Contraception also allows adequate planning and timing of pregnancy to optimise maternal and fetal outcomes (see Figure 2) and should be considered as a part of routine care.

\section{ADPKD and Fertility}

There is no evidence of impaired female fertility in ADPKD if renal function is normal. ${ }^{14}$ Some studies have reported an increased rate of ectopic pregnancy however numbers are small. ${ }^{15,16}$

Small studies report multiple abnormalities in males with ADPKD with regard to fertility, including necrospermia, ultrastructural flagellar defects, immotile sperm, seminal vesicle cysts and ejaculatory duct cysts. However, it is unknown how frequent the association between infertility and ADPKD is, and larger studies are required. ${ }^{14}$

\section{General Management of ADPKD}

Management of early stages of ADPKD and CKD generally is discussed in more detail elsewhere. ${ }^{17}$ The management of many aspects of ADPKD including genetic testing, cyst pain, and non-renal manifestations is also outlined in the Kidney Health Australia Caring for Australians with Renal Impairment (KHA-CARI) Guidelines. ${ }^{18}$ In brief, it is recommended that people maintain a healthy weight, regular exercise, and consume a moderate protein, sodium-restricted diet. Smoking avoidance or cessation and appropriate monitoring for hypertension and other cardiovascular risk factors are also important, with treatment as necessary. ${ }^{19}$ First-line treatment of hypertension is with angiotensin-converting enzyme inhibitors (ACEi), and if intolerant with angiotensin-receptor blockers (ARB), with additional agents added as necessary to maintain blood pressure to individualised targets. ${ }^{20}$ Management of hypertension during pregnancy is discussed in greater detail below.

Tolvaptan is a new therapy approved for ADPKD, providing additional treatment options for some patients, usually under strict selection criteria; however, it is not available in all countries as yet. Tolvaptan is an antagonist of the vasopressin V2 receptor. Cyclic adenosine monophosphate (cAMP) stimulates cyst epithelial cell proliferation and fluid secretion by these epithelial cells. cAMP is increased in ADPKD renal tissues and is produced by vasopressin-mediated activation of adenyl cyclase. ${ }^{21}$ Tolvaptan works by inhibiting vasopressinstimulated cAMP production, thereby inhibiting fluid secretion and cell proliferation. ${ }^{22-24}$

The CRISP trial $^{25}$ showed that TKV as measured by magnetic resonance imaging (MRI) was associated with reduced glomerular filtration rate (GFR) and progression to ESKD. TKV $>600 \mathrm{~mL} / \mathrm{m}$ predicts GFR decline within the next 8 years with $75 \%$ sensitivity and specificity. Tolvaptan, therefore, may be of therapeutic benefit to slow or halt progression to ESKD. ${ }^{25}$ The key trials (TEMPO $3: 4,{ }^{22}$ REPRISE $^{24}$ and TEMPO 4:4 $4^{23}$ ) demonstrated reduction of cyst growth and reduced rate of loss of GFR over time.

The current Pharmaceutical Benefit Scheme indications in Australia for tolvaptan are for use in adult patients with ADPKD with eGFR between $30-89 \mathrm{~mL} / \mathrm{min} / 1.73 \mathrm{~m}^{2}$ with rapidly decreasing eGFR $\left(>5 \mathrm{~mL} / \mathrm{min} / 1.73 \mathrm{~m}^{2} /\right.$ year $)$. Regarding use in pregnancy, animal data show embryofetal toxicity at low exposure and it has been shown to cross easily into breastmilk. ${ }^{26}$ Safety in human pregnancy or infant and child populations has not been studied. Therefore, tolvaptan is classified as pregnancy category $\mathrm{D}$ and is recommended to be avoided in pregnancy and breastfeeding. Impact on fertility is unknown.

\section{Physiologic Changes of Pregnancy}

During pregnancy, maternal systemic vascular resistance decreases, reducing afterload and increasing cardiac output. The kidneys increase in size and the urinary collecting system dilates. Vasodilation results in glomerular hyperfiltration and an increase in glomerular filtration rate with a concomitant fall in serum creatinine. There are changes to tubular function, with some increase in non-albumin urinary protein excretion and reduction in tubular glucose reabsorption. There is an increase in total body sodium and potassium associated with increase in plasma volume throughout pregnancy. ${ }^{27}$ Estimated GFR calculations are invalid and renal function is best measured with serum creatinine, noting that the reference range is lower than for non-pregnant women.

\section{CKD and Pregnancy}

It is estimated that $0.3-3 \%$ of the pregnancies are complicated by $\mathrm{CKD}^{28,29}$ including both women with known CKD entering pregnancy and women being diagnosed with CKD in pregnancy. Although previous generations 


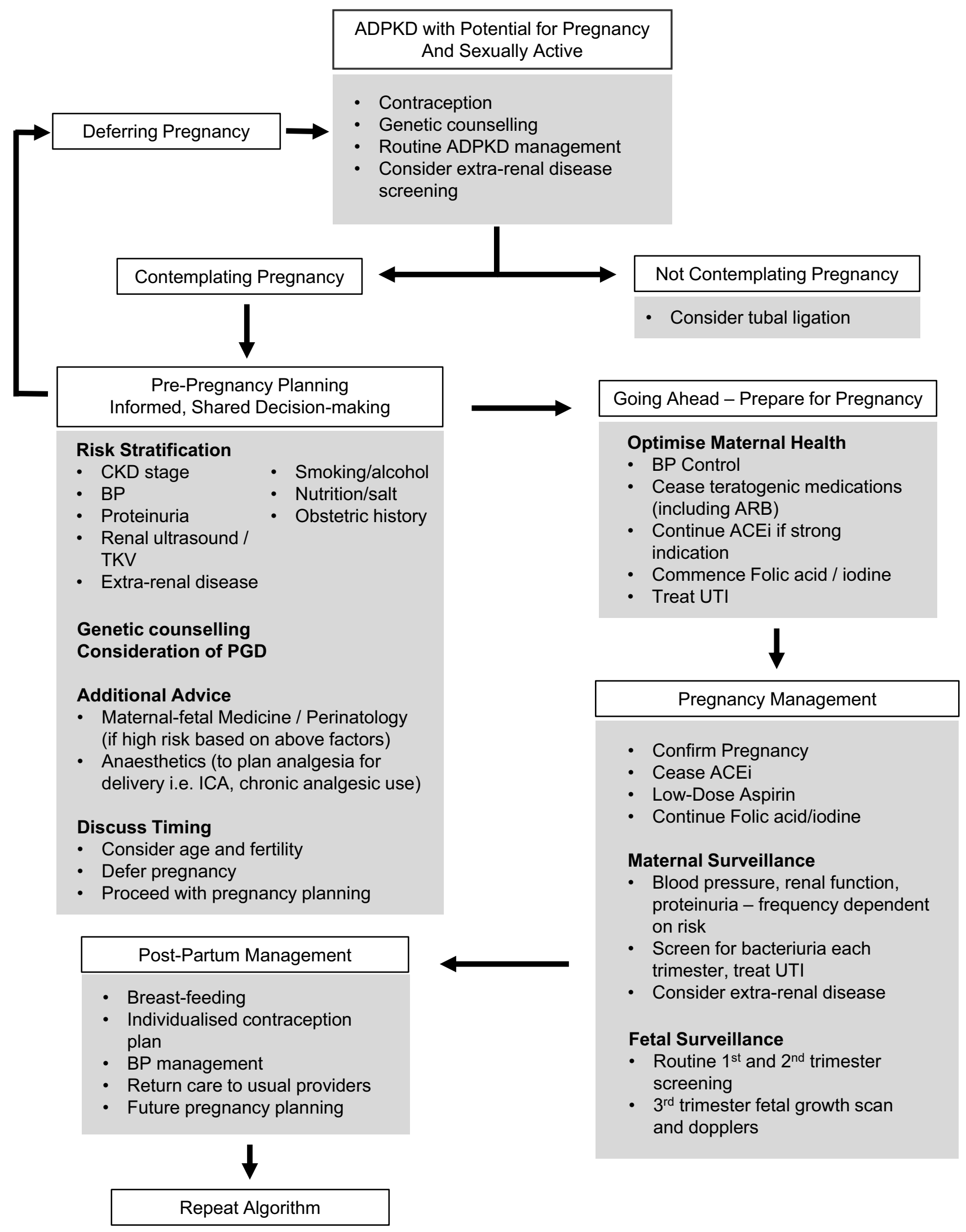

Figure 2 Algorithm for Pregnancy Management in Women with ADPKD.

Abbreviations: ADPKD, autosomal dominant polycystic kidney disease; CKD, chronic kidney disease; PGD, pre-implantation genetic diagnosis; BP, blood pressure; UTI, urinary tract infection; ACEi, angiotensin-converting enzyme; ARB, angiotensin receptor blocker; ICA, intra-cranial aneurysm; TKV, total kidney volume. 
of women with CKD were discouraged from pursuing pregnancy due to reports of poor outcomes, ${ }^{30}$ greater awareness around risks with appropriate monitoring and improvements in maternal-fetal care means more women are pursuing pregnancy successfully across the spectrum of disease severity. ${ }^{31}$

\section{Adverse Pregnancy-Related Outcomes in CKD}

Multiple review papers have discussed the adverse pregnancy-related outcomes associated with CKD. ${ }^{13,31,32}$ The key risk factors are CKD stage preconception, proteinuria and hypertension. Worsening CKD is associated with increased risk, both in severity and incidence, of adverse pregnancy-related outcomes, with the greatest risk of adverse outcomes seen in the dialysis population. ${ }^{32,33}$

Women with CKD are at greater risk of developing decline in renal function, hypertension, proteinuria and preeclampsia $^{29,31,33-35}$ in pregnancy. This increased risk is also seen in women with ADPKD. ${ }^{15,36}$ Obstetric outcomes of induction of labour and Caesarean section are also more common in CKD populations. ${ }^{29}$

This increased risk includes in women with "normal" renal function, or CKD stage 1 , even in the absence of hypertension and proteinuria. ${ }^{33,35}$ This is demonstrated in the increased relative risk of preeclampsia, pregnancyinduced hypertension and preterm delivery in otherwise well women undertaking pregnancy after kidney donation. ${ }^{37-39}$ This is particularly relevant to the ADPKD population, as most women with ADPKD may be entirely asymptomatic; however, given their structural renal disease and CKD stage 1, they are at increased risk of adverse pregnancy outcomes and warrant additional pregnancy care.

Fetal risks, particularly lower birth weight, small for gestation age (SGA), prematurity, neonatal intensive care unit (NICU) admission, intrauterine growth restriction (IUGR), and stillbirth are increased, with higher risk associated with increasingly severe CKD stage. ${ }^{29,33,40}$ There may be an increased risk of fetal malformation with moderate-severe CKD, but no association has been found with earlier-stage disease. ${ }^{41}$ Maternal and fetal risks are increased with multiple pregnancies. $^{42}$

Certain conditions such as immunological renal disease, systemic lupus erythematosus and vesicoureteric reflux have been shown to have worse pregnancy outcomes compared with other types of kidney disorders; however, this has not been particularly noted with ADPKD. ${ }^{29}$

\section{Patient Perspectives and Shared Decision-Making in Pregnancy Counselling}

Previous research has described multiple themes in relation to patient perspectives on CKD and pregnancy, ${ }^{43}$ including bodily failure, devastating loss and guilt at not achieving motherhood or gambling with maternal health. There are complex decisions when considering pregnancy, relating to women's own health and survival, outcomes for their future offspring, including inheritance of genetic disease, and expectations of partners and families. Health professionals' attitudes can lead to feelings of medical judgement and lack of support. Discussing the medical risks of pregnancy early in the disease course allows informed shared decision-making for pregnancy planning. Information provided needs to be well informed, up to date, and specific to women's health/disease status. The challenge for the health professional is to balance discussion of medical risks sensitively with patients' values of hope, autonomy and family. Disengagement of the patient can occur if the focus on risks and judgement predominate above hope and positivity. ${ }^{43}$ A good therapeutic relationship gives health professionals the best opportunity to optimise medical outcomes. ${ }^{44}$ See Figure 3.

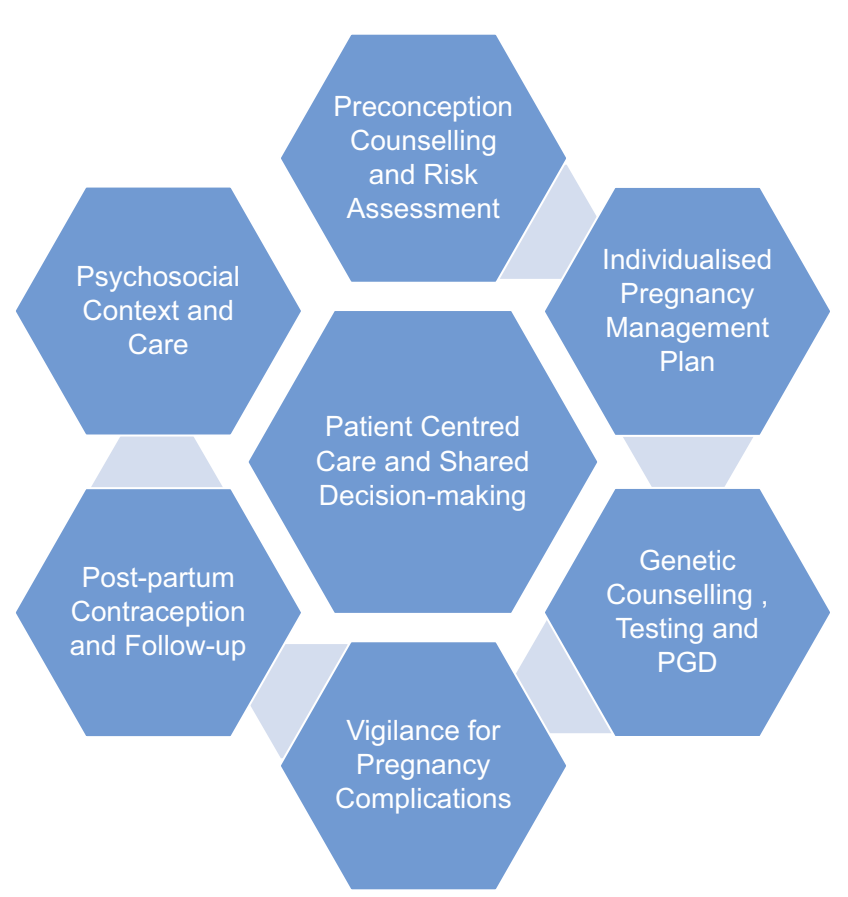

Figure 3 Suggested model of pregnancy care for women with ADPKD. Abbreviations: ADPKD, autosomal dominant polycystic kidney disease; PGD, preimplantation genetic diagnosis. 


\section{ADPKD Genetics and Genetic Counselling}

ADPKD is an autosomal dominant condition, meaning the offspring has $50 \%$ chance of inheriting a pathogenic variant from an affected parent. Genetic testing is not indicated in all patients with ADPKD; however, it is recommended for men and women seeking genetic counselling and family planning advice. ${ }^{45}$ Results of genetic testing, in addition to other factors described above, need to be explored with an experienced health professional to assist in decision-making regarding reproductive options well before pregnancy is planned. Personal and family experience (particularly events such as intracranial aneurysm and haemorrhage, or early ESKD), fertility issues and social circumstances also impact people's decisionmaking. ${ }^{46}$ Surveys of patients with ADPKD demonstrate mixed views on genetic testing and reproductive technology options. Less than $20 \%$ of the patients in one study would consider termination of pregnancy based on prenatal testing (as low as $4 \%$ in an older study ${ }^{47}$ ); however, over half of patients would consider pre-implantation genetic diagnosis (PGD), and almost 70\% believe PGD should be offered. ${ }^{48}$

\section{Pre-Implantation Genetic Diagnosis}

Pre-implantation genetic diagnosis (PGD) allows embryos without ADPKD pathogenic variants to be selected and implanted using in vitro fertilisation (IVF) technology. PGD requires prior identification of the pathogenic variant causing ADPKD in the affected parent. This may require testing of extended family members in the situation of novel variants to confirm pathogenicity. The variant cannot be identified in percentage of patients (around 10\%) using currently available techniques. ${ }^{45}$ Egg collection, in vitro fertilisation, then testing of embryos is performed. In ADPKD, as $50 \%$ of embryos are expected to be affected, the number of embryos likely to be required for successful pregnancy is increased. The unaffected embryo(s) are then implanted. IVF pregnancies are recognised to be associated with increased risks, ${ }^{49}$ particularly of multiple pregnancy, hypertensive disorders of pregnancy, preterm labour and delivery, low birth weight, a small increased risk of birth defects, as well as ovarian hyperstimulation syndrome and procedural risks. IVF also can be emotionally and financially burdensome, and access may be an issue for many people.

\section{Maternal and Fetal Monitoring During Pregnancy}

Women should have an initial review by a multidisciplinary team including an obstetrician and physician/obstetric nephrologist with expertise in high-risk pregnancy. Women should have regular monitoring of blood pressure, renal function, screening for proteinuria (using urine protein:creatinine ratio or urine albumin:creatinine ratio) and bacteriuria (see Figure 1). Frequency of testing should be based on individualised risk assessment depending on baseline parameters. Asymptomatic bacteriuria should be treated. Many women with ADPKD who are low risk (normal prepregnancy renal function, without hypertension or proteinuria) may be managed through lower risk care arrangements (ie with midwifery or primary care shared care).

In additional to routine fetal monitoring, we would suggest third trimester fetal ultrasound, for assessment of growth parameters, amniotic fluid assessment and uterine artery dopplers, in line with consensus recommendations for pregnancy with $\mathrm{CKD}^{50}$ (see Figure 1).

\section{Timing and Mode of Delivery}

Timing and mode of delivery will be individualised, based on the course of each pregnancy.

Mode of delivery should be based on usual obstetric indications, and caesarean section to avoid intra-cystic bleeding is not generally recommended.

\section{Common Complications of Pregnancies Affected by ADPKD Hypertensive Disorders of Pregnancy}

In pregnancy, hypertension is defined as systolic blood pressure (SBP) greater than or equal to $140 \mathrm{mmHg}$ and/or diastolic blood pressure (DBP) greater than or equal to $90 \mathrm{mmHg}$, using the average of at least two readings taken at least 15 mins apart. ${ }^{51}$

Hypertensive disorders of pregnancy occur in almost $10 \%$ of all pregnancies, and $2-5 \%$ of the women develop preeclampsia. ${ }^{52}$ All hypertensive disorders of pregnancy are more common in women with ADPKD. ${ }^{15,29,36}$ In one study, $16 \%$ developed new-onset hypertension during pregnancy. Twenty-five percent developed a hypertensive complication of pregnancy including $11 \%$ who developed preeclampsia. ${ }^{15}$ Normotensive women with ADPKD who develop any hypertensive disorder of pregnancy are at increased risk of developing chronic hypertension. ${ }^{15}$ 


\section{Aspirin Prophylaxis for Preeclampsia}

Low dose aspirin (75-150mg daily) is recommended from 12 weeks in women with risk factors for developing preeclampsia including CKD. ${ }^{51,53}$ There is minimal data on the role of aspirin in women with ADPKD; however, use in this population is recommended by extrapolation of data in other at-risk populations. ${ }^{54,55}$

\section{Chronic Hypertension}

Chronic hypertension is a common complication of ADPKD, and by definition includes hypertension identified in pregnancy prior to 20 weeks' gestation. ${ }^{51}$ Preexisting maternal hypertension in a ADPKD cohort with predominantly normal renal function pre-pregnancy has been found to be the most important independent risk factor for adverse pregnancy outcomes. ${ }^{15}$ Women with chronic hypertension are particularly at increased risk of preeclampsia (of women who were normotensive prior to their first pregnancy, $13(8 \%)$ developed preeclampsia vs $54 \%$ of those with chronic hypertension), fetal loss and maternal complications. ${ }^{15}$
Many antihypertensive agents used to control chronic hypertension are not suitable for use in pregnancy; in particular, ACEi and ARB exposure in the second and third trimester may lead to major birth defects including renal agenesis. Recent guidelines ${ }^{50,56}$ recommend in women with a strong indication for continued reninangiotensin blockade, ACEi can be stopped after pregnancy is confirmed. This is to prevent uncontrolled proteinuria during the period of time taken to conceive (unless there is significant concern regarding inadvertent exposure into pregnancy due to patient factors). In women without a strong indication for reninangiotensin blockade (non-proteinuric kidney disease), ACEi and ARB agents should be ceased, and patients stabilised on alternative antihypertensives are suitable for use in pregnancy (see Table 1) prior to attempts to conceive.

Early pregnancy is associated with reduction in blood pressure, with the nadir occurring around mid-pregnancy, and some women may require reduction or withdrawal of antihypertensive therapy during this time.

Table I Preferred Antihypertensive Medications in Pregnancy. Adapted from SOMANZ ${ }^{51}$ and Hypertension Canada ${ }^{64}$ Guidelines of Hypertension Management in Pregnancy. Additional Information sourced from Australian Medicines Handbook ${ }^{76}$

\begin{tabular}{|c|c|c|c|c|}
\hline $\begin{array}{l}\text { Antihypertensive } \\
\text { Medication }\end{array}$ & Dosage & $\begin{array}{l}\text { Mechanism of } \\
\text { Action }\end{array}$ & $\begin{array}{l}\text { Contra- } \\
\text { Indications }\end{array}$ & Practice Points/Side Effects \\
\hline \multicolumn{5}{|l|}{ First Line } \\
\hline Labetalol & $\begin{array}{l}100-400 \mathrm{mg} \\
\text { TDS }\end{array}$ & $\begin{array}{l}\text { Non-selective } \\
\text { beta-blocker } \\
\text { with mild alpha } \\
\text { vasodilator } \\
\text { effect }\end{array}$ & $\begin{array}{l}\text { Bradycardia, heart } \\
\text { block, } \\
\text { bronchospasm }\end{array}$ & $\begin{array}{l}\text { Side effects include bradycardia, bronchospasm, headache, } \\
\text { nausea, scalp tingling }\end{array}$ \\
\hline Nifedipine XR & $20-60 \mathrm{mg} B D$ & $\begin{array}{l}\text { Dihydropyridine } \\
\text { calcium channel } \\
\text { blocker }\end{array}$ & Aortic stenosis & $\begin{array}{l}\text { Side effects include headache, flushing, constipation, } \\
\text { peripheral oedema, tachycardia }\end{array}$ \\
\hline Methyl-dopa & $\begin{array}{l}250-750 \mathrm{mg} \\
\text { TDS }\end{array}$ & $\begin{array}{l}\text { Centrally acting } \\
\text { alpha adrenergic } \\
\text { agonist }\end{array}$ & Depression & $\begin{array}{l}\text { Slow onset of action } \\
\text { Side effects include dry mouth, sedation, blurred vision, and } \\
\text { depression (recommend ceased early in the post-partum } \\
\text { period) }\end{array}$ \\
\hline \multicolumn{5}{|l|}{ Second-Line } \\
\hline Clonidine & $75-300 \mu g$ TDS & $\begin{array}{l}\text { Centrally acting } \\
\text { alpha antagonist }\end{array}$ & $\begin{array}{l}\text { Bradycardia, } \\
\text { depression }\end{array}$ & $\begin{array}{l}\text { Withdrawal effects with rebound hypertension; } \\
\text { Avoid in breastfeeding (may cause reduced prolactin) }\end{array}$ \\
\hline Hydralazine & $25-50 \mathrm{mg} \mathrm{q8H}$ & $\begin{array}{l}\text { Arteriolar } \\
\text { vasodilator }\end{array}$ & $\begin{array}{l}\text { Idiopathic SLE/ } \\
\text { related diseases }\end{array}$ & $\begin{array}{l}\text { Side effects include flushing, headache, nausea, oedema, reflex } \\
\text { tachycardia }\end{array}$ \\
\hline Prazosin & $0.5-5 \mathrm{mg}$ TDS & Alpha-I blocker & Aortic stenosis & First-dose hypotension, orthostatic hypotension \\
\hline
\end{tabular}

Abbreviations: BD, twice daily; TDS, three times daily; q8H, 8 hourly; SLE, systemic lupus erythematosus. 


\section{Gestational or Pregnancy-Induced Hypertension}

Gestational or pregnancy-induced hypertension (PIH) is hypertension that develops after 20 weeks' gestation. ${ }^{51}$ Risk of adverse outcomes and development of preeclampsia is higher if earlier onset or more severe hypertension, where onset near term is associated with little increased risk. As for chronic hypertension, women with ADPKD are at increased risk of developing $\mathrm{PIH} .^{15,36}$

\section{Blood Pressure Targets in Pregnancy}

Optimal blood pressure control in pregnancy requires balancing the risks of overtreatment and undertreatment. Overtreatment of hypertension, resulting in impaired uteroplacental blood flow has been linked to an increased risk of SGA and low birth weight. ${ }^{57,58}$ Therefore, targets for blood pressure that may be applied in ADPKD outside of pregnancy (as low as $95 / 60$ to $110 / 75 \mathrm{mmHg}^{59}$ ) may not be appropriate in pregnancy. The Control of Hypertension in Pregnancy Study (CHIPS) investigated blood pressure control in women with PIH or chronic hypertension. ${ }^{60}$ More severe hypertension was found in the "less tight" (DBP < 100) group compared with "tight" (DBP < 85) group. Post hoc analysis demonstrated an association between the occurrence of severe hypertension and increased risk of pregnancy loss, the need for high-level neonatal care greater than $48 \mathrm{hrs}$, low birth weight and preterm delivery. ${ }^{61}$ A subsequent meta-analysis also found an association between less tight control and severe maternal hypertension. ${ }^{62}$ For the non-CKD population, the current National Institute for Clinical Excellence (NICE) guidelines recommend offering treatment if blood pressure is $140 / 90 \mathrm{mmHg}$ or above, and target a blood pressure on treatment of $135 / 85 \mathrm{mmHg}{ }^{63}$ Other guidelines are similar. ${ }^{51,64}$ Specific to patients with $\mathrm{CKD}$, blood pressure targets of less than $135 / 85 \mathrm{mmHg}$ are recommended (but not consistently less than $110 / 70 \mathrm{mmHg}) .{ }^{50}$

Antihypertensive medications commonly used in pregnancy are summarised in Table 2 .

\section{Preeclampsia}

Preeclampsia is a multisystem disorder unique to pregnancy. In women with ADPKD, the development of preeclampsia is one of the most important factors determining poor pregnancy/perinatal outcome. Development of preeclampsia in women with ADPKD significantly increased the risk of chronic hypertension and reduced the age at which chronic hypertension was diagnosed (34 years old vs 45 years old). ${ }^{15}$ It is associated with an increased risk of acute kidney injury (AKI); all instances of AKI in a cohort of women with ADPKD in pregnancy occurred in the setting of preeclampsia. ${ }^{15}$

Preeclampsia is defined as new-onset hypertension and proteinuria or other evidence of maternal end-organ dysfunction (ie hematological, neurological, hepatic, pulmonary edema) or fetal compromise after 20 weeks' gestation. ${ }^{51}$ The diagnosis in women with chronic hypertension and renal disease including baseline proteinuria can be extremely difficult and may be clinically indistinguishable from more benign gestational progression of hypertension and proteinuria, progression of underlying renal disease or other superimposed cause of renal impairment. Often when maternal or fetal indications for delivery are met, the underlying aetiology of deterioration may remain unclear.

Although not yet in widespread clinical use, angiogenic markers in the prediction and diagnosis of preeclampsia have a significant potential clinical role, including placental growth factor (PlGF) and soluble FMS-like tyrosine kinase1 (sFLT-1). sFLT-1/PIGF ratios have been studied in a CKD population, demonstrating significantly different values between patients with preeclampsia and those with CKD. ${ }^{65}$ In women with CKD and chronic hypertension between 20 and $36+6$ weeks, low maternal plasma PIGF has been demonstrated to have high diagnostic accuracy for prediction of superimposed preeclampsia requiring delivery within 14 days, ${ }^{66}$ suggesting a potential role in helping guide decision-making regarding admission and delivery.

There is currently no therapy that alters the pathophysiology of preeclampsia, and delivery is the only definitive treatment strategy. Severe preeclampsia requires urgent delivery. In non-severe preeclampsia and chronic hypertension/PIH, timing of delivery is dependent on gestational age, balanced with severity of disease and measures of fetal well-being. In women with $\mathrm{CKD}$, specialist input into the additional maternal risks (ie of $\mathrm{AKI}$ and irreversible progression of $\mathrm{CKD}$ ) is recommended and delivery plans must be individualised.

Post-partum resolution of preeclampsia can take days or longer, and some features of the disease may worsen initially following delivery; therefore, ongoing close monitoring is required. In those with $\mathrm{CKD}$, blood pressure, proteinuria and renal function may not return to pre-pregnancy baseline. Enalapril (or captopril for short-term use) is safe for use in breastfeeding term infants and is the first-line treatment in most women with ADPKD post-partum. 
Table 2 Summary of Causes of Acute Abdominal Pain in Pregnancy

\begin{tabular}{|c|c|c|c|}
\hline Obstetric & Non-Obstetric & $\begin{array}{l}\text { Exacerbated by } \\
\text { Pregnancy }\end{array}$ & Extra-Abdominal \\
\hline $\begin{array}{l}\text { Early Pregnancy: } \\
\text { Ectopic pregnancy } \\
\text { Molar pregnancy } \\
\text { Ovarian cyst: torsion, hemorrhage, } \\
\text { rupture } \\
\text { Degeneration of uterine fibroids } \\
\text { Round ligament pain } \\
\text { Late Pregnancy: } \\
\text { Placental abruption } \\
\text { Acute fatty liver of pregnancy } \\
\text { Abdominal pregnancy } \\
\text { Hemolysis elevated liver enzymes low } \\
\text { platelet count syndrome } \\
\text { Preeclampsia } \\
\text { Ruptured uterus } \\
\text { Fibroid degeneration } \\
\text { Fallopian tube torsion } \\
\text { Uterine torsion } \\
\text { Ruptured rectus muscle } \\
\text { Polyhydramnios } \\
\text { Symphysis diastasis } \\
\text { Intraperitoneal bleed }\end{array}$ & $\begin{array}{l}\text { Surgical: } \\
\text { Appendicitis } \\
\text { Cholecystitis } \\
\text { Biliary colic } \\
\text { Acute pancreatitis } \\
\text { Peptic ulcer } \\
\text { Urolithiasis } \\
\text { Intestinal obstruction } \\
\text { Inflammatory bowel disease } \\
\text { Ruptured aneurysm, including of splenic artery } \\
\text { Trauma } \\
\text { Medical: } \\
\text { Gastroenteritis } \\
\text { Porphyria } \\
\text { Sickle cell crisis } \\
\text { Deep vein thrombosis } \\
\text { Cystic complications including rupture, } \\
\text { hemorrhage and infection in ADPKD }\end{array}$ & $\begin{array}{l}\text { Gastro-esophageal } \\
\text { reflux disease } \\
\text { Gallbladder disease } \\
\text { Cystitis } \\
\text { Pyelonephritis } \\
\text { Musculoskeletal pain }\end{array}$ & $\begin{array}{l}\text { Cardiac pain } \\
\text { Non-specific abdominal } \\
\text { pain } \\
\text { Pleuritic pain } \\
\text { Psychological drug abuse } \\
\text { or withdrawal } \\
\text { Herpes zoster infection }\end{array}$ \\
\hline
\end{tabular}

Note: Copyright (c) 2019. Adapted from Zachariah SK, Fenn M, Jacob K, Arthungal SA, Zachariah SA. Management of acute abdomen in pregnancy: current perspectives. Int J Womens Health. 2019;1 I:119-134. ${ }^{91}$

Abbreviation: ADPKD, Autosomal dominant polycystic kidney disease.

\section{Urinary Tract Infection}

Pregnancy is a time of increased risk of UTI. This is thought to relate to physiological changes in pregnancy, including hydroureter secondary to effects of increased progesterone, changes in the renal tubules causing glycosuria and aminoaciduria, relative immunosuppression/immune changes and in later pregnancy the mechanical effect of gravid uterus. Urinary stasis contributes to increase the risk of pyelonephritis. ${ }^{67}$ Pyelonephritis has been associated with prematurity, lowbirth weight and pregnancy loss. ${ }^{29}$ Women with ADPKD have a further increased risk of UTI (14\%) in pregnancy compared with non-ADPKD controls. ${ }^{36}$ Increased screening for bacteriuria is recommended in this population with a low threshold for commencing antibiotic prophylaxis for the duration of pregnancy ${ }^{68}$ Early recognition of symptoms, urine collection for microscopy, culture and sensitivity and commencement of appropriate empiric antibiotic therapy (with particular consideration to safety in pregnancy and local epidemiology).

Cyst infection accounts for up to $10 \%$ of the hospital admissions related to complications of ADPKD. ${ }^{69}$ The gold standard for diagnosis is aspiration of purulent fluid from an infected cyst; however, the diagnosis is usually based on clinical criteria. ${ }^{69}$ Pyuria is frequently absent, although cyst infection may be secondary to ascending urinary tract infection. ${ }^{70}$ Ultrasound and CT imaging might not assist with diagnosis; however, contrast $\mathrm{CT}$, magnetic resonance imaging (MRI) and positron-emission tomography (PET) may be more useful imaging modalities, ${ }^{71}$ with MRI the preferred modality in pregnancy. Aggressive management of cyst infection in pregnancy is important, due to the potential adverse events associated with urinary tract infection in pregnancy (as discussed above). In addition to safety in pregnancy and local epidemiology, penetration of antibiotics into cysts needs to be considered (water-soluble antibiotics penetrate cysts poorly compared with lipid-soluble antibiotics ${ }^{72}$ ), recognising the potential need for prolonged antibiotics for cyst infections. Large cysts may require surgical drainage.

\section{Renal Tract Obstruction}

During pregnancy, physiological hydronephrosis can develop, with an incidence of $60-80 \%$. Changes can be 
noted on ultrasound in the second trimester and they resolve by 6 weeks postpartum. ${ }^{67}$ Incidence of hydronephrosis in ADPKD is rare and related to secondary pathology, such as ureteric stricture. ${ }^{73}$ Single parapelvic cysts identified on routine imaging may be misdiagnosed as hydronephrosis. ${ }^{74}$

\section{Acute Abdominal Pain}

Women with ADPKD may experience acute abdominal pain. The differential diagnosis is summarised in Table 2 . Cyst complications include rupture, hemorrhage and infection. Cyst infection typically presents with sudden onset unilateral diffuse flank pain, accompanied by signs of infection. Cyst rupture and hemorrhage is also typically acute onset, unilateral flank pain, but often associated with point tenderness (although pain may be more diffuse if subcapsular hematoma results). These differentials should be considered in an approach to assessing acute abdominal pain.

\section{Chronic Pain}

Chronic pain due to capsular distension and other factors can occur in patients with ADPKD and guidelines on management are detailed elsewhere. ${ }^{75}$ Severe chronic pain syndromes should be managed in conjunction with a pain specialist, and anaesthetic review completed in advance of delivery. Paracetamol is considered safe during all trimesters of pregnancy. Non-steroidal anti-inflammatory drugs (NSAIDs) are avoided in pregnancy and used with caution in those with CKD. Opioid analgesics may cause respiratory depression in newborns and withdrawal effects may occur in neonates of dependent mothers. ${ }^{76}$

\section{Intracranial Aneurysm}

Intracranial aneurysms are vascular lesions with increased risk of rupture, which occur in approximately $1.8 \%$ of the general population. The frequency in the asymptomatic ADPKD population is around $9-17 \%$, higher in those with a family history. ${ }^{77}$ Risk factors for rupture included size and location of aneurysm, smoking, hypertension and alcohol excess, and there is noted to be familial clustering of ICA rupture.

Guidelines for screening are based on expert opinion and low-quality data, and generally recommend selective screening in those with a family history or other high-risk features (high-risk occupation, uncontrolled hypertension, prior to major surgery, smokers, those requiring anticoagulants, patient anxiety regarding risk). ${ }^{77,78}$ Although pregnancy is associated with hemodynamic and hormonal changes that can influence aneurysm development and growth, guidelines do not include pregnancy as an indication for screening.

Women who are known to have an intracranial aneurysm should be discussed with an experienced neurosurgical department where possible. Data on the risk of aneurysm rupture in pregnancy, delivery and postnatally are conflicting, with some studies suggesting risk is not increased compared with background risk, ${ }^{79,80}$ however, careful consideration of blood pressure control and mode of delivery is still recommended. Caesarean section is often favoured to avoid hemodynamic changes associated with vaginal delivery. Avoidance of a prolonged second stage with adequate analgesia is another strategy to reduce hemodynamic stress. Data regarding the efficacy of these approaches are lacking.

\section{Polycystic Liver Disease}

Polycystic liver disease is the most common extra-renal manifestation of ADPKD and is associated with both PKD1 and PKD2. ${ }^{81}$ Cyst incidence increases with age, with $33 \%$ incidence by 25 and $94 \%$ by $45 .{ }^{82}$ An incidence of $44 \%$ was noted in one cohort of pregnant women. ${ }^{36}$ The majority of patients remain asymptomatic with preserved liver function. ${ }^{81}$ A proportion of patients develop massive polycystic liver disease that is associated with abdominal mass effect, pain, early satiety, fatigue and cyst infection. ${ }^{83}$ Other complications are rare. There are no reports on pregnancy-associated complications of polycystic liver disease, and management of complications arising in pregnancy should follow that in the non-pregnant population. Estrogen exposure is associated with increased risk of polycystic liver disease, through pregnancy, estrogencontaining contraceptives ${ }^{84}$ and hormone replacement therapy ${ }^{85}$ Estrogen-containing contraception should therefore be avoided to reduce the risks of worsening liver disease.

\section{Post-Partum Care and Follow-Up of Mother and Baby}

Usual post-partum care includes pain management, support with care of the newborn, including feeding and other skills and psychological support (acknowledging the high risk of mental health issues in the post-partum period, especially in the setting of pregnancy complications). Although NSAIDs are used routinely for post-partum analgesia, they should be avoided in women with ADPKD, especially where there is superimposed preeclampsia. 
Venous thromboembolism prophylaxis should be considered based on risk factor assessment, particularly if nephrotic range proteinuria is present,${ }^{50}$ which although uncommon in ADPKD can occur with superimposed preeclampsia.

An individualised plan should be made to review renal function and blood pressure post-partum. The frequency of immediate follow-up will depend on the individual circumstances. All women should have longer-term monitoring of renal parameters.

Contraception needs to be addressed post-partum, with progesterone-only methods favoured in the post-partum period for multiple reasons, including in the context of $\mathrm{CKD},{ }^{50}$ breastfeeding ${ }^{86}$ and polycystic liver disease (as discussed above).

There is evidence to suggest there are long-term impacts of pregnancy on maternal health and ADPKD. The development of preeclampsia is associated with poorer long-term cardiovascular outcomes. ${ }^{87}$ Some data suggest in women with ADPKD, having more than three or four pregnancy is associated with accelerated renal impairment. ${ }^{15,88}$ However, reassuringly, if a woman with ADPKD has an uncomplicated pregnancy, subsequent pregnancies are likely to also progress without complication. ${ }^{15}$

Babies are at higher risk of lower birth weight, SGA, prematurity, NICU admission and IUGR as discussed above when born to mothers with CKD. ADPKD has also been associated with trends to worse neonatal outcomes; however, numbers are smaller. ${ }^{36}$ Neonatal factors (such as low birth weight and prematurity) may also be associated with the progression of renal disease long-term. ${ }^{89}$

Although manifestations of ADPKD usually arise later in life, disease does occur in children, and proteinuria and hypertension may accelerate progression. Therefore, children at risk of inheriting ADPKD are recommended to have blood pressure screened every 2 years after the age of 5 years. ${ }^{90}$ Genetic testing and ultrasound screening in children remain controversial, and genetic counselling should be sought prior to further investigations as discussed in more detail elsewhere. ${ }^{46,90}$

\section{Conclusion}

In summary, ADPKD has important implications in pregnancy affecting maternal and fetal well-being. It is important for women, their families and health professionals to be aware of these implications and where possible engage in prepregnancy planning, careful pregnancy care and adequate follow-up. This should be done with a multidisciplinary team assisting in shared decision-making, including genetics, fertility, nephrology and obstetrics, in order to optimise maternal and fetal outcomes.

\section{Disclosure}

Dr Shilpanjali Jesudason declared that she works for Kidney Health Australia who has received financial support from Otsuka which is the drug company that makes tolvaptan to treat polycystic kidney disease. This support is outside the submitted work and has no relations to this study. The authors report no other conflicts of interest in this work.

\section{References}

1. Lanktree MB, Haghighi A, Guiard E, et al. Prevalence estimates of polycystic kidney and liver disease by population sequencing. $J \mathrm{Am}$ Soc Nephrol. 2018;29(10):2593-2600. doi:10.1681/ASN.2018050493

2. Willey CJ, Blais JD, Hall AK, Krasa HB, Makin AJ, Czerwiec FS. Prevalence of autosomal dominant polycystic kidney disease in the European Union. Nephrol Dial Transplant. 2017;32(8):1356-1363. doi:10.1093/ndt/gfw240

3. Spithoven EM, Kramer A, Meijer E, et al. Renal replacement therapy for autosomal dominant polycystic kidney disease (ADPKD) in Europe: prevalence and survival-an analysis of data from the ERAEDTA Registry. Nephrol Dial Transplant. 2014;29(Suppl 4):iv15iv25. doi:10.1093/ndt/gfu017

4. Fernando MR, Dent H, McDonald SP, Rangan GK. Incidence and survival of end-stage kidney disease due to polycystic kidney disease in Australia and New Zealand (1963-2014). Popul Health Metr. 2017;15(1):7. doi:10.1186/s12963-017-0123-7

5. Cornec-le Gall E, Torres VE, Harris PC. Genetic complexity of autosomal dominant polycystic kidney and liver diseases. J Am Soc Nephrol. 2018;29(1):13-23. doi:10.1681/ASN.2017050483

6. Cornec-le Gall E, Audrezet MP, Chen JM, et al. Type of PKD1 mutation influences renal outcome in ADPKD. J Am Soc Nephrol. 2013;24(6):1006-1013. doi:10.1681/ASN.2012070650

7. Chebib FT, Torres VE. Autosomal dominant polycystic kidney disease: core curriculum 2016. Am J Kidney Dis. 2016;67(5):792-810. doi:10.1053/j.ajkd.2015.07.037

8. Inker LA, Astor BC, Fox CH, et al. KDOQI US commentary on the 2012 KDIGO clinical practice guideline for the evaluation and management of CKD. Am J Kidney Dis. 2014;63(5):713-735. doi:10.1053/j. ajkd.2014.01.416

9. Johnson DW, Atai E, Chan M, et al. KHA-CARI guideline: early chronic kidney disease: detection, prevention and management. Nephrology (Carlton). 2013;18(5):340-350. doi:10.1111/nep.12052

10. Johnson DW, Jones GR, Mathew TH, et al. Chronic kidney disease and automatic reporting of estimated glomerular filtration rate: new developments and revised recommendations. Med J Aust. 2012;197 (4):224-225. doi:10.5694/mja11.11468

11. Jesudason S, Grace BS, McDonald SP. Pregnancy outcomes according to dialysis commencing before or after conception in women with ESRD. Clin J Am Soc Nephrol. 2014;9(1):143-149. doi:10.2215/ CJN.03560413

12. Wyld ML, Clayton PA, Kennedy SE, Alexander SI, Chadban SJ. Pregnancy outcomes for kidney transplant recipients with transplantation as a child. JAMA Pediatr. 2015;169(2):e143626. doi:10.1001/ jamapediatrics.2014.3626

13. Fitzpatrick A, Mohammadi F, Jesudason S. Managing pregnancy in chronic kidney disease: improving outcomes for mother and baby. Int J Womens Health. 2016;8:273-285. doi:10.2147/IJWH.S76819 
14. Vora N, Perrone R, Bianchi DW. Reproductive issues for adults with autosomal dominant polycystic kidney disease. Am J Kidney Dis. 2008;51(2):307-318. doi:10.1053/j.ajkd.2007.09.010

15. Chapman AB, Johnson AM, Gabow PA. Pregnancy outcome and its relationship to progression of renal failure in autosomal dominant polycystic kidney disease. J Am Soc Nephrol. 1994;5(5):1178-1185.

16. Milutinovic J, Fialkow PJ, Agodoa LY, Phillips LA, Bryant JI. Fertility and pregnancy complications in women with autosomal dominant polycystic kidney disease. Obstet Gynecol. 1983;61 (5):566-570.

17. Kidney Health Australia. Melbourne. Chronic Kidney Disease (CKD) management in general practice (3rd Edition); 2015. Available from https://kidney.org.au/health-professionals/prevent/chronic-kidneydisease-management-handbook. Accessed January 3, 2020..

18. Rangan GK, Alexander SI, Campbell KL, et al. KHA-CARI guideline recommendations for the diagnosis and management of autosomal dominant polycystic kidney disease. Nephrology (Carlton). 2016;21(8):705-716. doi:10.1111/nep.12658

19. Campbell KL, Rangan GK, Lopez-Vargas P, Tong A. KHA-CARI autosomal dominant polycystic kidney disease guideline: diet and lifestyle management. Semin Nephrol. 2015;35(6):572-581. (). doi:10.1016/j.semnephrol.2015.10.008

20. Mallett A, Lee VW, Mai J, Lopez-Vargas P, Rangan GK. KHA-CARI autosomal dominant polycystic kidney disease guideline: pharmacological management. Semin Nephrol. 2015;35(6):582-589.. doi:10.10 16/j.semnephrol.2015.10.009

21. Torres VE, Harris PC. Strategies targeting cAMP signaling in the treatment of polycystic kidney disease. J Am Soc Nephrol. 2014;25 (1):18-32. doi:10.1681/ASN.2013040398

22. Torres VE, Chapman AB, Devuyst O, et al. Tolvaptan in patients with autosomal dominant polycystic kidney disease. $N$ Engl J Med. 2012;367(25):2407-2418. doi:10.1056/NEJMoa1205511

23. Torres VE, Chapman AB, Devuyst O, et al. Multicenter, open-label, extension trial to evaluate the long-term efficacy and safety of early versus delayed treatment with tolvaptan in autosomal dominant polycystic kidney disease: the TEMPO 4:4 Trial. Nephrol Dial Transplant. 2018;33(3):477-489. doi:10.1093/ndt/gfx043

24. Torres VE, Chapman AB, Devuyst O, et al. Tolvaptan in later-stage autosomal dominant polycystic kidney disease. $N$ Engl J Med. 2017;377(20):1930-1942. doi:10.1056/NEJMoa1710030

25. Grantham JJ, Torres VE, Chapman AB, et al. Volume progression in polycystic kidney disease. $N$ Engl J Med. 2006;354(20):2122-2130. doi:10.1056/NEJMoa054341

26. Furukawa M, Umehara K, Kashiyama E. Nonclinical pharmacokinetics of a new nonpeptide V2 receptor antagonist, tolvaptan. Cardiovasc Drugs Ther. 2011;25(Suppl 1):S83-S89. doi:10.1007/ s10557-011-6357-x

27. Odutayo A, Hladunewich M. Obstetric nephrology: renal hemodynamic and metabolic physiology in normal pregnancy. Clin J Am Soc Nephrol. 2012;7(12):2073-2080. doi:10.2215/CJN.00470112

28. Munkhaugen J, Lydersen S, Romundstad PR, Wideroe TE, Vikse BE, Hallan S. Kidney function and future risk for adverse pregnancy outcomes: a population-based study from HUNT II, Norway. Nephrol Dial Transplant. 2009;24(12):3744-3750. doi:10.1093/ndt/ gfp320

29. Fitzpatrick A, Venugopal K, Scheil W, McDonald SP, Jesudason S. The spectrum of adverse pregnancy outcomes based on kidney disease diagnoses: a 20-year population study. Am J Nephrol. 2019;49 (5):400-409. doi:10.1159/000499965

30. Jones DC, Hayslett JP. Outcome of pregnancy in women with moderate or severe renal insufficiency. $N$ Engl J Med. 1996;335 (4):226-232. doi:10.1056/NEJM199607253350402

31. Hladunewich MA, Melamed N, Bramham K. Pregnancy across the spectrum of chronic kidney disease. Kidney Int. 2016;89 (5):995-1007. doi:10.1016/j.kint.2015.12.050
32. Wiles KS, Nelson-Piercy C, Bramham K. Reproductive health and pregnancy in women with chronic kidney disease. Nat Rev Nephrol. 2018;14(3):165-184. doi:10.1038/nrneph.2017.187

33. Piccoli GB, Cabiddu G, Attini R, et al. Risk of adverse pregnancy outcomes in women with CKD. J Am Soc Nephrol. 2015;26 (8):2011-2022. doi:10.1681/ASN.2014050459

34. Piccoli GB, Cabiddu G, Castellino S, et al. A best practice position statement on the role of the nephrologist in the prevention and follow-up of preeclampsia: the Italian Study Group on Kidney and Pregnancy. J Nephrol. 2017;30(3):307-317. doi:10.1007/s40620-017-0390-1

35. Zhang JJ, Ma XX, Hao L, Liu LJ, Lv JC, Zhang H. A systematic review and meta-analysis of outcomes of pregnancy in CKD and CKD outcomes in pregnancy. Clin J Am Soc Nephrol. 2015;10 (11):1964-1978. doi:10.2215/CJN.09250914

36. Wu M, Wang D, Zand L, et al. Pregnancy outcomes in autosomal dominant polycystic kidney disease: a case-control study. J Matern Fetal Neonatal Med. 2016;29(5):807-812. doi:10.3109/147670 58.2015 .1019458

37. Garg AX, Nevis IF, McArthur E, et al. Gestational hypertension and preeclampsia in living kidney donors. $N$ Engl J Med. 2015;372 (2):124-133. doi:10.1056/NEJMoa1408932

38. Ibrahim HN, Akkina SK, Leister E, et al. Pregnancy outcomes after kidney donation. Am J Transplant. 2009;9(4):825-834.

39. Reisaeter AV, Roislien J, Henriksen T, Irgens LM, Hartmann A. Pregnancy and birth after kidney donation: the Norwegian experience. Am J Transplant. 2009;9(4):820-824.

40. Piccoli GB, Fassio F, Attini R, et al. Pregnancy in CKD: whom should we follow and why? Nephrol Dial Transplant. 2012;27 (Suppl 3):iii111-iii118. doi:10.1093/ndt/gfs302

41. Haseler E, Melhem N, Sinha MD. Renal disease in pregnancy: fetal, neonatal and long-term outcomes. Best Pract Res Clin Obstet Gynaecol. 2019;57:60-76. doi:10.1016/j.bpobgyn.2019.01.018

42. Piccoli GB, Arduino S, Attini R, et al. Multiple pregnancies in CKD patients: an explosive mix. Clin J Am Soc Nephrol. 2013;8(1):41-50. doi: $10.2215 /$ CJN.02550312

43. Tong A, Brown MA, Winkelmayer WC, Craig JC, Jesudason S. Perspectives on pregnancy in women with CKD: a semistructured interview study. Am J Kidney Dis. 2015;66(6):951-961. doi:10.1053/ j.ajkd.2015.08.023

44. Jesudason S, Tong A. The patient experience of kidney disease and pregnancy. Best Pract Res Clin Obstet Gynaecol. 2019;57:77-88. doi:10.1016/j.bpobgyn.2018.12.003

45. Tchan M, Savige J, Patel C, et al. KHA-CARI autosomal dominant polycystic kidney disease guideline: genetic testing for diagnosis. Semin Nephrol. 2015;35(6):545-549. doi:10.1016/j.semnephrol.2015.10.007

46. Patel C, Tchan M, Savige J, et al. KHA-CARI autosomal dominant polycystic kidney disease guideline: genetics and genetic counseling. Semin Nephrol. 2015;35(6):550-556. doi:10.1016/j.semnephrol.2015.10.003

47. Sujansky E, Kreutzer SB, Johnson AM, Lezotte DC, Schrier RW, Gabow PA. Attitudes of at-risk and affected individuals regarding presymptomatic testing for autosomal dominant polycystic kidney disease. Am J Med Genet. 1990;35(4):510-515. doi:10.1002/(ISSN)1096-8628

48. Swift O, Vilar E, Rahman B, Side L, Gale DP. Attitudes in patients with autosomal dominant polycystic kidney disease toward prenatal diagnosis and preimplantation genetic diagnosis. Genet Test Mol Biomarkers. 2016;20(12):741-746. doi:10.1089/gtmb.2016.0050

49. Sullivan-Pyke CS, Senapati S, Mainigi MA, Barnhart KT. In Vitro fertilization and adverse obstetric and perinatal outcomes. Semin Perinatol. 2017;41(6):345-353. doi:10.1053/j.semperi.2017.07.001

50. Wiles K, Chappell L, Clark K, et al. Clinical practice guideline on pregnancy and renal disease. BMC Nephrol. 2019;20(1):401. doi:10.1186/s12882-019-1560-2

51. Society of Obstetric Medicine Australia and New Zealand. SOMANZ guidelines for the management of hypertensive disorders of pregnancy; 2015. Available from https://www.somanz.org/guide lines.asp. Accessed January 3, 2020. 
52. Saftlas AF, Olson DR, Franks AL, Atrash HK, Pokras R. Epidemiology of preeclampsia and eclampsia in the United States, 1979-1986. Am J Obstet Gynecol. 1990;163(2):460-465. doi:10.10 16/0002-9378(90)91176-D

53. Webster K, Fishburn S, Maresh M, Findlay SC, Chappell LC, Guideline C. Diagnosis and management of hypertension in pregnancy: summary of updated NICE guidance. BMJ. 2019;366:15119. doi:10.1136/bmj.15119

54. Henderson JT, Whitlock EP, O’Connor E, Senger CA, Thompson JH, Rowland MG. Low-dose aspirin for prevention of morbidity and mortality from preeclampsia: a systematic evidence review for the U.S. preventive services task force. Ann Intern Med. 2014;160 (10):695-703. doi:10.7326/M13-2844

55. Rolnik DL, Wright D, Poon LC, et al. Aspirin versus placebo in pregnancies at high risk for preterm preeclampsia. $N$ Engl $\mathrm{J} \mathrm{Med}$. 2017;377(7):613-622. doi:10.1056/NEJMoa1704559

56. Cabiddu G, Castellino S, Gernone $\mathrm{G}$, et al. A best practice position statement on pregnancy in chronic kidney disease: the Italian Study Group on Kidney and Pregnancy. J Nephrol. 2016;29(3):277-303.

57. von Dadelszen P, Magee LA. Fall in mean arterial pressure and fetal growth restriction in pregnancy hypertension: an updated metaregression analysis. J Obstet Gynaecol Can. 2002;24(12):941-945. doi:10.1016/S1701-2163(16)30592-8

58. von Dadelszen P, Ornstein MP, Bull SB, Logan AG, Koren G, Magee LA. Fall in mean arterial pressure and fetal growth restriction in pregnancy hypertension: a meta-analysis. Lancet. 2000;355 (9198):87-92. doi:10.1016/S0140-6736(98)08049-0

59. Schrier RW, Abebe KZ, Perrone RD, et al. Blood pressure in early autosomal dominant polycystic kidney disease. $N$ Engl J Med. 2014;371(24):2255-2266. doi:10.1056/NEJMoa1402685

60. Magee LA, von Dadelszen P, Rey E, et al. Less-tight versus tight control of hypertension in pregnancy. $N$ Engl J Med. 2015;372 (5):407-417. doi:10.1056/NEJMoa1404595

61. Magee LA, von Dadelszen P, Singer J, et al. The CHIPS randomized controlled trial (control of hypertension in pregnancy study): is severe hypertension just an elevated blood pressure? Hypertension. 2016;68 (5):1153-1159. doi:10.1161/HYPERTENSIONAHA.116.07862

62. Abalos E, Duley L, Steyn DW, Gialdini C. Antihypertensive drug therapy for mild to moderate hypertension during pregnancy. Cochrane Database Syst Rev. 2018;10:CD002252.

63. NICE. Hypertension in pregnancy: diagnosis and management. Available from https://www.nice.org.uk/guidance/ng133. Accessed January 3, 2020.

64. Butalia S, Audibert F, Cote AM, et al. Hypertension Canada's 2018 guidelines for the management of hypertension in pregnancy. Can J Cardiol. 2018;34(5):526-531. doi:10.1016/j.cjca.2018.02.021

65. Rolfo A, Attini R, Nuzzo AM, et al. Chronic kidney disease may be differentially diagnosed from preeclampsia by serum biomarkers. Kidney Int. 2013;83(1):177-181. doi:10.1038/ki.2012.348

66. Bramham K, Seed PT, Lightstone L, et al. Diagnostic and predictive biomarkers for pre-eclampsia in patients with established hypertension and chronic kidney disease. Kidney Int. 2016;89(4):874-885. doi:10.1016/j.kint.2015.10.012

67. Mandal D, Saha MM, Pal DK. Urological disorders and pregnancy: an overall experience. Urol Ann. 2017;9(1):32-36. doi:10.4103/0974 7796.198901

68. The Renal Association. United kingdom. clinical practice guideline pregnancy and renal disease; 2018. Available from https://renal.org/ wp-content/uploads/2019/09/FINAL-Pregnancy-GuidelineSeptember-2019.pdf. Accessed January 3, 2020..

69. Sallee M, Rafat C, Zahar JR, et al. Cyst infections in patients with autosomal dominant polycystic kidney disease. Clin J Am Soc Nephrol. 2009;4(7):1183-1189. doi:10.2215/CJN.01870309

70. Lantinga MA, Casteleijn NF, Geudens A, et al. Management of renal cyst infection in patients with autosomal dominant polycystic kidney disease: a systematic review. Nephrol Dial Transplant. 2017;32 (1):144-150. doi:10.1093/ndt/gfv452
71. Lantinga MA, Drenth JP, Gevers TJ. Diagnostic criteria in renal and hepatic cyst infection. Nephrol Dial Transplant. 2015;30(5):744-751. doi:10.1093/ndt/gfu227

72. Hamanoue S, Suwabe T, Ubara Y, et al. Cyst infection in autosomal dominant polycystic kidney disease: penetration of meropenem into infected cysts. BMC Nephrol. 2018;19(1):272. doi:10.1186/s12882018-1067-2

73. Kistler AD, Poster D, Wuthrich RP, Serra AL. Hydronephrosis in autosomal dominant polycystic kidney disease. Kidney Int. 2009;76 (12):1297. doi:10.1038/ki.2009.309

74. Ma TL, Neild GH. Parapelvic cyst misdiagnosed as hydronephrosis. Clin Kidney J. 2013;6(2):238-239. doi:10.1093/ckj/sfs189

75. Savige J, Tunnicliffe DJ, Rangan GK. KHA-CARI autosomal dominant kidney disease guideline: management of chronic pain. Semin Nephrol. 2015;35(6):607-611. (). doi:10.1016/j.semnephrol.2015.10.013

76. Australian Medicines Handbook. Australia. Available from https:// amhonline.amh.net.au. Accessed March 20, 2020. Updated July 2019. Accessed December 30, 2019.

77. Lee VW, Dexter MA, Mai J, Vladica P, Lopez-Vargas P, Rangan GK. KHA-CARI autosomal dominant polycystic kidney disease guideline: management of intracranial aneurysms. Semin Nephrol. 2015;35 (6):612-617. (). doi:10.1016/j.semnephrol.2015.10.014

78. Ars E, Bernis C, Fraga G, et al. Spanish guidelines for the management of autosomal dominant polycystic kidney disease. Nephrol Dial Transplant. 2014;29(Suppl 4):iv95-iv105. doi:10.1093/ndt/gfu186

79. Kim YW, Neal D, Hoh BL. Cerebral aneurysms in pregnancy and delivery: pregnancy and delivery do not increase the risk of aneurysm rupture. Neurosurgery. 2013;72(2):143-149. (). doi:10.1227/ NEU.0b013e3182796af9

80. Tiel Groenestege AT, Rinkel GJ, van der Bom JG, Algra A, Klijn CJ. The risk of aneurysmal subarachnoid hemorrhage during pregnancy, delivery, and the puerperium in the Utrecht population: case-crossover study and standardized incidence ratio estimation. Stroke. 2009;40 (4):1148-1151. doi:10.1161/STROKEAHA.108.539700

81. D'Agnolo HM, Drenth JP. Risk factors for progressive polycystic liver disease: where do we stand? Nephrol Dial Transplant. 2016;31 (6):857-859. doi:10.1093/ndt/gfv417

82. Bae K, Park B, Sun H, et al. Segmentation of individual renal cysts from MR images in patients with autosomal dominant polycystic kidney disease. Clin J Am Soc Nephrol. 2013;8(7):1089-1097. doi:10.2215/CJN.10561012

83. Chauveau D, Fakhouri F, Grunfeld JP. Liver involvement in autosomal-dominant polycystic kidney disease: therapeutic dilemma. J Am Soc Nephrol. 2000;11(9):1767-1775.

84. van Aerts RMM, Bernts LHP, Gevers TJG, et al. Estrogen-containing oral contraceptives are associated with polycystic liver disease severity in premenopausal patients. Clin Pharmacol Ther. 2019;106 (6):1338-1345. doi:10.1002/cpt.v106.6

85. Sherstha R, McKinley C, Russ P, et al. Postmenopausal estrogen therapy selectively stimulates hepatic enlargement in women with autosomal dominant polycystic kidney disease. Hepatology. 1997;26 (5):1282-1286. doi:10.1002/hep.510260528

86. The Faculty of Sexual and Reproductive Healthcare. United kingdom. FSRH guideline contraception after pregnancy; 2017. Available from: https://www.fsrh.org/standards-and-guidance/documents/contraceptionafter-pregnancy-guideline-january-2017/. Accessed January 3, 2020.

87. Brouwers L, van der Meiden-van Roest AJ, Savelkoul C, et al. Recurrence of pre-eclampsia and the risk of future hypertension and cardiovascular disease: a systematic review and meta-analysis. BJOG. 2018;125(13):1642-1654. doi:10.1111/1471-0528.15394

88. Gabow PA, Johnson AM, Kaehny WD, et al. Factors affecting the progression of renal disease in autosomal-dominant polycystic kidney disease. Kidney Int. 1992;41(5):1311-1319. doi:10.1038/ki.1992.195

89. Luyckx VA, Bertram JF, Brenner BM, et al. Effect of fetal and child health on kidney development and long-term risk of hypertension and kidney disease. Lancet. 2013;382(9888):273-283. doi:10.1016/S0140-6736(13)60311-6 
90. The Renal Association. United Kingdom. clinical practice guideline monitoring children and young people with, or at risk of developing autosomal dominant polycystic kidney disease (ADPKD). 2018. Available from https://renal.org/guidelines/. Accessed January 3, 2020.
91. Zachariah SK, Fenn M, Jacob K, Arthungal SA, Zachariah SA. Management of acute abdomen in pregnancy: current perspectives. Int J Womens Health. 2019;11:119-134. doi:10.2147/IJWH.S151501

\section{Publish your work in this journal}

The International Journal of Women's Health is an international, peerreviewed open-access journal publishing original research, reports, editorials, reviews and commentaries on all aspects of women's healthcare including gynecology, obstetrics, and breast cancer. The manuscript management system is completely online and includes a very quick and fair peer-review system, which is all easy to use. Visit http://www.dovepress.com/testimonials.php to read real quotes from published authors. 